\title{
Flipping The Practice Based Pathology Laboratory - Can It Support Development of Practitioner Capability For Trainee Pathologists in Gynaecological Cytopathology?
}

\author{
Sara Smith ${ }^{1}$, Raji Ganesan ${ }^{2}$ and Jan Martin ${ }^{1}$
}

1. School of Biomedical Science and Physiology, Faculty of Science and Engineering, University of Wolverhampton, Wolverhampton, WV10 7BQ, United Kingdom

2. Birmingham Cytology Training Centre, Birmingham Women's NHS FoundationTrust, Mindelsohn Way, Birmingham, West Midlands B15 2TG, United Kingdom

Corresponding Author

Dr Jan Martin CBiol CSci FHEA FIBMS FRSB

Deputy Head of School of Biomedical Science and Physiology

Principal Lecturer for Accreditation and Development

Faculty of Science and Engineering

University of Wolverhampton

Wulfruna Street

Wolverhampton

WV1 1LY

Tel: +441902 321154

Fax:+441902 322714

j.martin@wlv.ac.uk 


\section{Abstract}

This study investigated the role of 'flipping' the practice based pathology laboratory and classroom to support the development of trainee pathologist practitioners' in the field of gynaecological cytopathology; addressing development of their knowledge and practical application in the clinical setting. Content rich courses traditionally involve lecture led delivery which restricts tutors from adopting approaches that support greater student engagement in the topic area and application of knowledge to practice. We investigated the role of 'flipping' the practice based pathology laboratory and classroom where 'virtual lectures' were accessed outside of 'class time' allowing more time for students to engage in active learning under the supervision of a consultant histopathologist. 'Flipping' was used to support two gynaecological cytopathology training courses with cohorts of eight trainee pathologists on the first course and six on the second. Lectures were made available to the trainees to watch before attending the workshops. The workshops consisted of group activities and individual practical exercises allowing trainees to review and report on patient practice cases with the support of their peers and tutors. Focus group sessions were held after each course, allowing trainee pathologists to reflect on their experiences. Discussions were transcribed and thematic analysis was used to capture key themes discussed by the trainees. Trainees' identified that 'flipping' provided them with more time during face-to-face sessions, enabling a greater depth of questioning and engagement with the consultant histopathologists. Having already watched the lectures, trainees were able to attend the sessions having identified areas in which they needed additional support and development. Trainee pathologists reported they had more time to concentrate on developing their skills and practise under the guidance of the consultant histopathologists so developing their capability in gynaecological cytopathology. The role of alternative methods of delivery such as 'flipping' are suggested for short courses designed to support practitioner capability and continued professional development.

\section{Introduction}

Lectures are still a major component of post-graduate teaching. Content-rich courses in general result in a lecture led delivery of information but this can present barriers to the adoption of pedagogical approaches that support individuals' engagement; lectures being ineffective vehicles for promoting deep learning and the development of practical skills. In the traditional approach the lecturer delivers material to students, with 
directed reading and assignments used to reinforce this material. This provides very limited face-to-face discussion time or active learning.

Post-graduate education is designed to support the development of greater subject or specialist knowledge as well as developing the capability of the individual within their chosen profession. An environment, both social and physical, that promotes deep learning and encourages learning via active involvement is more likely to support this; helping individuals to question the assumptions that inform their capability and practice [1]. There is an abundance of literature discussing 'flipping' and the role of the 'flipped' classroom to support such an approach $[2,3,4]$. The basic format for all though involves students accessing 'virtual lectures' outside of contact time which provides time for students to engage in activities and collaborative learning during contact time; without sacrificing time to cover course content.

Although the importance of the interactive nature of learning [5], active learning [6] and inverted classrooms [7] have all been recognised for several years, it has only been within the last decade [8] that the term 'flipped classroom' has been used to describe teaching where students study new topics before class which subsequently facilitates using in class time for support with the more difficult concepts. Even though a flipped classroom provides an opportunity to enhance the curriculum [9], incorporate a variety of different novel styles [10] and provide more student-tutor interaction during face-to-face sessions [11] flipping is not without its demands. Tutors are required to spend extra time preparing pre-class material [12] students must have access to reliable technology [10] and students must also be motivated to engage with the topics before attending class [13]. While additional components such as online quizzes, online discussion groups and online tutorials may be incorporated into pre-class videos, engagement with the required technology relies on the students being independent learners in order to facilitate a successful flip. Despite these challenges, several studies have indicated that flipped classrooms can be effective in many different subject areas including legal information literacy [14] counselor education [15] and mathematics [16].

In this paper we present details of the second phase of a participatory action research study into the role of the 'flipped classroom' in supporting the delivery of courses aligned to professional practice. The first phase addressed our approach to supporting students studying on an MSc Module (Diagnostic Cellular Pathology) in 
a post 1992 University [17]. Learning from this experience we applied a similar approach in a course for trainee pathologists, undertaking gynaecological cytology training at a regional training centre as part of their professional training for practice. The approach used was based around two well acknowledged teaching approaches: Just- in-Time-Teaching (JiTT) [18] and Peer instruction [19]. JiTT was designed to create a direct link between in-class and out-of-class activities via web-based assignments; forming a feedback loop between learning in-class and outside experiences. Individuals enter the classroom ready to participate actively in classroom activities having completed the web-based activities [20]. The effectiveness of this pedagogical approach has been demonstrated in a wide variety of different disciplines including foreign languages [21], business statistics [22] and calculus [23] where its implementation has enhanced understanding [24], engagement [25] and active learning [26].

Peer instruction uses students in the teaching process. This builds upon the concept that individuals develop complex reasoning skills most effectively when actively engaged with the material they are studying. Cooperative activities are an excellent way to engage individuals effectively [1]. Several studies have demonstrated that students perceive peer instruction as engaging and useful [27] and that it is effective in enhancing learning [28] as it provides an opportunity for students to view conceptual understanding questions from an alternative perspective [29]. The combination of these two approaches is referred to as either 'inverting' the classroom or 'flipping' the classroom: the fundamental idea behind this approach is that more time can be dedicated to active learning with tutor and peer support and feedback being provided in-class [30].

One of the many different training courses currently provided by the Cytology Training Centre is a specific 2day training course covering several different aspects of gynaecological cytopathology. Trainee pathologists from a range of NHS Trusts attend these short gynaecological cytopathology training courses. The course, which has been designed to prepare trainee pathologists for taking the Gynaecological Cytology FRCPath Part 2 Exam, includes a range of gynaecological cytopathology topics and includes training on the NHS Cervical Screening Programme, squamous and glandular cervical cytology and NHSCSP reporting and management guidelines for cervical cytology. The course also includes tips and techniques to help prepare for the exam and 
a mock gynaecological cytopathology FRCPath Part 2 exam with feedback and discussion of the cases. Lectures are delivered by pathologists and workshops/multi-header sessions are supported by advanced practitioners. As well as being very 'theory heavy', they also provide the trainees with access to a wide range of different patient case-study based material which they can review to assist in developing their skills in this field. Many of the patient cases available for them to review are from rare or complex conditions so time spent at the microscope in the practice based pathology laboratory, discussing cases with peers and tutor in a supportive environment, is invaluable. As such, these procedures lend themselves particularly well to JiTT and peer instruction pedagogical approaches which were chosen for this study. Trainee pathologists attending the courses have a range of experience within gynaecological cytopathology and may also have undertaken their initial studies outside of the UK. Flipping would allow the lecture sessions to be accessed by the trainee pathologists prior to attendance at the training centre providing them with the ability to control the pace of their learning.

\section{Methodology}

As practitioner-researchers the aim of our inquiry was to improve the learning experiences of the trainees enabling them to fully engage with the material delivered - supporting a deep approach to learning and to develop their skills for practice. A participatory approach informed the inquiry, situated within the constructivist paradigm and focusing upon participants as co-creators of understanding within the area being investigated [31]. Constructivism views learning as an active process where knowledge is constructed from, and shaped by, experience. Learning is interaction-building on what students already know.

As outlined an initial study was undertaken which investigated the use of flipped lectures as a means of enhancing the learning experience of students on a postgraduate module [17]. Module content was delivered using both flipped and non-flipped sessions to facilitate comparison of the two different approaches. Questionnaires, focus groups and interviews were used to evaluate the outcomes of the study. We found that flipping the classroom supported students in a variety of different ways. Student evaluation results from questionnaires demonstrated that flipped sessions enhanced student motivation to engage with the topic resulting in students who were both better prepared for taught sessions and who felt more challenged to think during class. Focus group evaluation showed that flipped sessions improved understanding of the topic, 
enhanced the student learning experience and maximised the opportunity for students to become active rather than passive learners empowering them to take charge of their own learning. Results from interviews confirmed that students agreed with evaluation of the study data. This initial study highlighted the advantages of 'flipping' the classroom at postgraduate level as a means of increasing student confidence, developing a collaborative in class learning community and improving the overall learning experience of students.

This paper describes the experiences of trainee pathologists and tutors involved in 'flipping' the classroom and practice based pathology laboratory and our perceptions of whether this approach enhances both learning and teaching experiences; supporting the development of greater subject or specialist knowledge as well as developing the capability of the individual. Our research questions were:

\section{- Can "flipping" be successfully applied in other areas of training to support learning in pathology?}

\section{- What are the perceptions of trainee pathologists of "flipping" as a pedagogical tool?}

\section{Methods}

Drawing upon the comments and experiences of the first phase [17] of the inquiry 'flipping' was introduced to support the gynaecological cytopathology training courses for trainee pathologists delivered at a regional training centre. The 'flipped' sessions consisted of one theory based cytopathology lecture session and another session providing trainees with exam 'hints and tips'. These were delivered to support two courses running at the centre with a cohort of eight trainees (three male and five female) on the first course and six (three male and three female) on the second. Trainees were between 28 to 35 years of age with an ethnicity of $60 \%$ White and $40 \%$ Asian. The recordings were restricted to 30 minutes maximum duration based upon postgraduate student feedback and full details were provided to the trainees on how to access and use the lecture capture site. A focus group session, which was conducted by the practitioner-researchers, was held at the end of each of the two courses where the flipped sessions were used. Table 1 details the questions which were asked during the focus groups. These sessions were recorded, transcribed and thematic analysis [32] used to identify key themes identified by the trainees. Consultant histopathology tutors also provided a reflective account of their own experiences and perceptions of the 'flipping' delivery. 
Table 1 Focus Group Questions

\begin{tabular}{|c|l|}
\hline Number & Question \\
\hline 1 & Have you watched the flipped video? \\
\hline 2 & Did you all watch all of the flipped video? \\
\hline 3 & Did you watch all of the flipped video in one go? \\
\hline 4 & Did you watch the flipped video more than once? \\
\hline 5 & Do you think the flipped video would be useful as a revision tool? \\
\hline 6 & Did seeing the lecture in advance give you more confidence when you came to do the workshop? \\
\hline 7 & How could the flipped video be improved? \\
\hline 8 & How did you find the length of the video? \\
\hline 9 & How long would you like the video to be available for, following the workshop? \\
\hline 10 & $\begin{array}{l}\text { Is the current format of the video lecture sufficient or would it be better to have some form of } \\
\text { interactive sessions embedded within the video? }\end{array}$ \\
\hline 11 & Would some form of interaction that checked your understanding of the topic be useful? \\
\hline 12 & Have you any suggestions for how we could move this forward and improve it for the next time? \\
\hline 13 & Did the video assist in helping you to identify what you need extra help with during the session? \\
\hline 14 & Did you find it a useful resource? \\
\hline 15 & Do you think that you took it in more since you were able to listen to it in your own time? \\
\hline 16 & Are there any topics that you think would be better delivered in a traditional non-flipped format? \\
\hline 17 & Was it a lot of information to take in, in one go? \\
\hline 18 & Was the length of the presentation acceptable? \\
\hline 19 & $\begin{array}{l}\text { Do you need to be able to see the lecturer actually present in the video delivering the presentation } \\
\text { or would PowerPoint with a voice over be sufficient? }\end{array}$ \\
\hline 20 & Do you have any other comments? \\
\hline
\end{tabular}

\section{Results}

Trainees (100\%) were very positive about being involved in the inquiry and found the use of 'flipping' to be a positive experience. $100 \%$ of trainees reported that they had watched the flipped video, had watched all of it, and had done so all in one go. A few trainees (12\%) stated that they had watched the videos more than once with one trainee reporting that the second viewing had provided an excellent opportunity to make useful notes. Key themes emerged from analysis of the transcripts around the utility of the 'flipped' lectures. The ability to have a reusable resource was identified by $100 \%$ of trainees as essential for supporting initial learning experiences:

I like to be able to hear things more than once - for me the more times I hear something the more it is likely to embed itself into my brain.

The thing that I found useful with this is you could go back, flick back.

It was also acknowledged by $100 \%$ of trainees as supporting further knowledge development:

It is not only before the class that it is good. ..after the class too as a revision tool.... especially before the exam... but also even afterwards as revision 
An important benefit of this approach was its capacity for supporting individuals to develop their capability in specialist cancer areas. By reducing contact time spent delivering lectures more time could be spent focusing upon supporting application to the clinical situation:

.....for me the best part of these [courses] are the multi-header sessions [multi-head microscope within the practice based pathology laboratory]. The lectures are a good background, but a lot of it is theory that I already know.... or should know....and it's the multi-header with the finer points, and little snippets of help that you get at the multi-header, that are more useful. I am happy with the lecture set up as it was [flipped].

One trainee did acknowledge initial apprehension about the "flipped" lecture:

I did wonder initially if this was going to be a bit odd - was she going to read through all of the PowerPoint slides? But it was more than that. it wasn't just a reading of the PowerPoints she explained the main key concepts and of course this then meant that there was longer to do the multiheader sessions.

$100 \%$ of trainees agreed that not only did the approach allow more time for practical application but also ensured greater engagement with the topic area and a chance to identify areas for further support - and to obtain that support from peers and tutor:

Personally I would favour this [flipped] - you come away from the course then with a much better understanding. Instead of just listening to someone talk to you, you actually have all that time putting things into practice and that is when I find the questions really come forth because if you are working through it in a practical sense that is when you come across your problems - it doesn't occur to you when it's just a lecture.

Trainee pathologists attending the courses were at different stages in their training and with different experiences. One of the benefits highlighted in the initial postgraduate phase of the inquiry was that those less confident or inexperienced students found the 'flipped' approach gave them more confidence and supported their learning more. This also came out as a theme in the second phase:

I think a lot of the time the material required depends upon the audience and the degree of experience they have in certain areas. If they are earlier in their career they may want to target specific things and so the [flipped] videos are very useful and a good idea. 
Provision of the lectures before attendance on the course was also seen as beneficial to enable a standard to be set of the course and expected learning outcomes:

Yes I think by giving the lectures beforehand you are sort of establishing a standard. So if you are a very junior person and you are starting from scratch you can read up on it, on everything beforehandyou wouldn't have the experience - which is what the workshops are for - but you can read around the relevant material - so at least you have the theory before going into it.

One of the more experienced trainee pathologists was very open with their comments about their experiences on training courses and highlighted an advantage of using 'flipped' lectures which as tutors we hadn't considered:

There is also another advantage that I have found, this sounds rude, but you get some people who give a very disciplined and controlled lecture and others lecturing style is friendlier and they say "just stop me if you want to ask anything, ask questions at anytime". You will get people who will ask a question every 30 seconds and the constant interruption and the lecturer is "yes I am going to get to that" and then that lecture can be stretched much longer than it should. I sat through with a group of people who just kept asking - we actually had to cut the lectures in half since they wanted to talk around everything, absolutely everything. If they were at home with it they could watch the whole thing watch it again, watch it a third time and if they still have questions they can put it in a list and ask instead of every three seconds "well what if it is this" and he goes " hang on that's slide five" - it can be very frustrating for other people

With the lecture capture system used for the study you could view the PowerPoint slides and the video of the lecture at the same time, just watch the lecturer delivering the lecture (PowerPoint slides in the background of video) or just have the sound over the PowerPoint slides. This allowed the trainees to choose the most appropriate format for them:

I just looked at the PowerPoint [with sound but no tutor image]

I think that if it is someone who is enthusiastic in their delivery then you sort of engage more whereas if it is someone who is very monotonous well you actually wouldn't want to see them. 
Trainees liked to be able to make the choice:

I actually think it depends upon the individual - some people need to have a person there to make them pay attention - otherwise I might just potter about while it's on as if listening to radio 4.

The benefit of the 'flipped' approach is that it provides those with different learning preferences and approaches to their studies the ability to make choices. For the consultant histopathology tutors, initially there was a need to adjust to a different approach to delivering teaching sessions and the 'hang-up' of being recorded:

I felt uncomfortable initially with the actual lecture capture on the day. I felt very self-conscious. I had to consciously relax.

However, the benefits were soon realised and both tutors noticed improved engagement and a greater depth of questioning around the topic area:

I was impressed at the thoughtful questions that they [trainee pathologists] put...... It made me feel that it was worth it.... They were more knowledgeable at the multi header [microscope]

\section{Discussion}

As practitioner researchers the initial aim of this study was to improve the learning experience for trainee pathologists; supporting the development of greater subject or specialist knowledge as well as developing the practical application of cytopathology knowledge in a clinical setting. In agreement with other studies, the initial frequency and duration of trainee pathologists engagement with pre class material confirms reports from other investigations which have shown that students complete work prior to class in a single session [32].

Our results also confirm previously published studies which have suggested that the 'flipped' approach supports greater engagement [33] in the topics being taught and encourages a 'deep' approach to learning [32]. A flipped classroom has been demonstrated to improve student motivation [34] and this was clearly evident in our study where trainees stated that the 'flipped' approach prepared them well for the face-to-face sessions which in turn provided them with greater motivation to engage with their peers and tutors during inclass discussions. They felt more challenged to think during the sessions rather than taking on the role of passive learner. This was acknowledged by each of the tutors: trainees led discussions and asked thoughtful questions. In the traditional sessions questioning tended to be tutor led and guided. 
The benefit of development of a learning community was acknowledged. Learning communities support knowledge construction, where knowledge is not simply "discovered" but is socially constructed [35]. Collaborative learning supports greater understanding in individuals and a deeper approach to learning [36]. Learning becomes personalised and focuses more on the needs of each individual. In this study, the 'flipped' approach encouraged the development of such learning communities more than the traditional approach: this may have been due to having more time during the class, the students feeling more confident to discuss the topic areas having had time to watch and re-watch the videos, or simply due to the tutors approach and conscious appreciation of developing a more peer led approach. For the trainee pathologists, the availability of teaching materials for them to review, covering a wide range of conditions which would not normally be accessible in their own laboratories means that they want to spend their time on these - not in lecture sessions.

This investigation has addressed, to our knowledge, the first use of flipping in a practice based pathology laboratory. The study focused on the perceptions of trainee pathologists and tutors of "flipping" as a pedagogical tool in this novel arena and their perceptions of whether this approach enhanced both learning and teaching experiences. Phase 1 of our flipping study investigated the use of flipping on an MSc Diagnostic Cellular Pathology module. Currently there is conflicting evidence within the literature regarding the impact of flipping the classroom on assessment. While some studies have reported a significant increase in exam grades [37] there are reports where flipping has only improved exam performance in the bottom third [38], has improved performance for some topics but not others [39] or has failed to demonstrate any improvement in measured learning gains [40]. Following publication of the results from phase 1 [17], we carried out an analysis of exam results from the MSc module. This showed that post graduate students performed better on questions relating to the 'flipped' sessions and interestingly were more likely to choose these topics in the exam. This supported their reflective statements highlighting how the approach encouraged greater engagement in the topic area, even though in the questionnaire they felt they had met the learning outcomes for each topic area. 
Phase 1 was undertaken on a small cohort of only 10 post graduate students but the findings are encouraging. The focus of phase 2 , which is reported in this paper, is limited in its approach as it investigates the experiences and perceptions of a small number of trainee pathologists with a flipped approach to a practice based pathology laboratory. The next phase of this flipped study will involve using a measure to assess what trainee pathologists actually learn and will involve subsequent cohorts of trainee pathologists in evaluating further the impact of flipping the classroom upon their achievement in assessment, an aspect of flipping which is equivocal within the current literature.

\section{Conclusion}

Is it just another pedagogic fad?

We would suggest that 'flipped' lectures are not an alternative to the delivery of all teaching - but that they are just one approach/tool in a wider framework of instructional methods available to tutors to support engagement and learning. Similar conclusions have been articulated by other studies [41]. However, we would suggest that the potential of the 'flipped' learning approach lies in how it allows delivery of direct instruction outside of the classroom opening up time and space inside the classroom to engage in more influential instructional practices and to individualise learning. The approach maximises the opportunity for individuals to become active learners, empowering them to take charge of their own learning. For tutors, the 'flipped' approach encourages a re-evaluation of teaching and a focus on addressing the specific needs of each cohort. The 'flipped' approach releases more time for discussion in-class allowing greater evaluation of the individuals' progress and understanding of the topic area. Although initially quite time-consuming to prepare for the sessions, tutors found they enjoyed the flipped workshops more, got to know the trainees better, developing a good rapport allowing trainees to feel more able to question and ask for help. We, therefore, feel that

'flipping' supports training in areas such as gynaecological cytology supporting a more active-learning approach and allowing trainee pathologists to focus upon developing their capability with the support of peers and tutors. 


\section{Acknowledgements}

The authors wish to thank the Pathological Society of Great Britain and Ireland for Educational Grant Scheme funding (EGS 201304 02) which facilitated carrying out this research study.

\section{References}

1. Lizzio A, Wilson K. 2004. Action learning in Higher Education: an investigation of its potential to develop professional capability. Stud High Educ. 29(4): 469-488

2. Bates S, Galloway R. 2012. The inverted classroom in a large enrolment introductory physics course: a case study. Proceedings of the HEA STEM Learning and Teaching Conference; April 12-13; Imperial College, London.

3. Lage M, Platt G, Treglia M. 2000. Inverting the Classroom: a Gateway to Creating an Inclusive Learning Environment. J Econ Educ. 31(1): 30-43

4. Prober C, Heath C. 2000. Lecture Halls without Lectures - A Proposal for Medical Education. N Engl J Med. 366(18): 1657-1659.

5. Dewey J, Dewey E. 1915. School of to-morrow. New York: Dutton.

6. Bonwell C, Eison J. 1991. Active Learning: Creating Excitement in the Classroom. Information Analyses - ERIC Clearinghouse on Higher Education 71:3.

7. Lage MJ, Platt GJ, Treglia M. 2000. Inverting the Classroom: A Gateway to Creating an Inclusive Learning Environment. The Journal of Economic Education, 31, 30-43.

8. Noonoo S. 2012, Flipped Learning Founders Set the Record Straight. The Journal. Transforming Education Through Technology. Available from http://thejournal.com/articles/2012/06/20/flipped-learning-founders$\underline{q-a n} . .$.

9. Bishop JL, Verleger MA. 2013. The flipped classroom: A survey of the research. Paper presented at the meeting of American Society of Engineering Education, Atlanta, GA. Retrieved from http://dts.drake.edu/wp-content/uploads/sites/2/2014/03/The-Flipped-Classroom-A-Survey-of-the-

$\underline{\text { Research.pdf }}$

10. Hamdan N. McKnight P. McKnight, K, Arfstrom KM 2013. A review of flipped learning. Retrieved from http://flippedlearning.org/cms/lib07/VA01923112/Centricity/Domain/41/ 
11. Milman NB. 2012. The flipped classroom strategy: What is it and how can it best be used? Distance Learning, 9, 85-87.

12. Educause. 2012. 7 things you should know about flipped classrooms. Retrieved from http://www. educause.edu/library/resources/7-things-you-should-know-about-flipped-classrooms

13. Nilson, L. 2013. Flipping your classroom: What does it mean? PowerPoint presented at the Office of Teaching Effectiveness and Innovation, Clemson University, Clemson, SC.

14. Lemmer, C.A. 2013. A view from the flip side: Using the "inverted classroom" to enhance the legal information literacy of the of the international LL. M. student. Law Library Journal, 105(4), 461-491.

15. Moran K, Milsom A. 2015. The Flipped Classroom in Counselor Education. Counselor Education \& Supervision Volume 54: 32-43

16. Mattis, KV. 2015. Flipped Classroom versus Traditional Textbook Instruction: Assessing Accuracy and Mental Effort at Different Levels of Mathematical Complexity Technology, Knowledge and Learning, 20 (2); 231-248

17. Smith S, Brown D, Purnell E, Martin J. 2014. 'Flipping' the Postgraduate Classroom: supporting the student experience. In: Layne P, Lake P, editors. Global Innovation of Teaching and Learning in Higher Education. Transgressing Boundaries: Professional Learning and Development in Schools and Higher Education. Springer Publishing.

18. Novak GN, Patterson E, Gavrin CW. 1999. Just-in-Time Teaching: Blending active Learning and Web Technology. Prentice Hall.

19. Mazur E. 1997. Peer Instruction: A User's Manual. Prentice Hall; Series in Educational Innovation.

20. Novak G, Paterson E. 2010. An Introduction to Just-In-Time-Teaching (JiTT). In: Simkins S, Maier M, editors. Just in Time Teaching: Across the Discipline, Across the Academy. Stylus Publishing.

21. Abreu L, Knouse S. 2014 Just-in-Time Teaching: A Tool for Enhancing Student Engagement in Advanced Foreign Language Learning Journal of Effective Teaching, 14 (2): 49-68

22. Bangs J. 2012. Transforming a Business Statistics Course with Just-in-Time Teaching American Journal of Business Education, 5 (1): 87-94

23. Natarajan R, Bennett A. 2014. Improving Student Learning of Calculus Topics via Modified Just-in-Time Teaching Methods PRIMUS, 24 (2): 149-159 
24. Formica SP, Easley JL, Spraker MC. 2010. Transforming Common-Sense Beliefs into Newtonian Thinking through Just-in-Time Teaching Physical Review Special Topics - Physics Education Research, 6 (2): 020106

25. Guertin LA, Zappe SE, Kim H. 2007 Just-in-Time Teaching Exercises to Engage Students in an IntroductoryLevel Dinosaur Course Journal of Science Education and Technology, 16 (6): 507-514

26. Wanner T. 2015. Enhancing Student Engagement and Active Learning through Just-in-Time Teaching and the Use of Powerpoint. International Journal of Teaching and Learning in Higher Education, 27 (1): 154-163

27. Relling AE, Giuliodori MJ. 2015 Effect of Peer Instruction on the Likelihood for Choosing the Correct Response to a Physiology Question Advances in Physiology Education, 39 (3): 167-171

28. Gok T. 2015 An Investigation of Students' Performance after Peer Instruction with Stepwise ProblemSolving Strategies International Journal of Science and Mathematics Education, 13 (3): 561-582

29. Wood AK, Galloway RK, Hardy J, Sinclair CM. 2014. Analyzing Learning during Peer Instruction Dialogues: A Resource Activation Framework. Physical Review Special Topics - Physics Education Research, 10 (2) 020107

30. Bergmann J, Sams A. 2012. Flip Your Classroom: Reach Every Student in Every Class Every Day International Society for Technology in Education

31. Reason P. 1999. Integrating Action and Reflection Through Co-operative Inquiry. Manage Learn. 30(2): 207226.

32. Braun V, Clarke V. 2006. Using thematic analysis in psychology. Qual Res Psychol. 3(2): 77-101.

33. McLean S, Attardi S M, Faden L, Goldszmidt, M. 2016. Flipped Classrooms and Student Learning: Not Just Surface Gains. Advances in Physiology Education, 40 (1): 47-55

34. Clark KR. 2015. The Effects of the Flipped Model of Instruction on Student Engagement and Performance in the Secondary Mathematics Classroom Journal of Educators Online, 12 (1): 91-115.

35. Abeysekera L; Dawson P. 2015. Motivation and Cognitive Load in the Flipped Classroom: Definition, Rationale and a Call for Research. Higher Education Research and Development, 34 (1): 1-14

36. Zhao C, Khu G. 2004. Learning Communities and Student Engagement. Res High Educ. 45(2): 115-38.

37. Prince M. 2004. Does Active Learning Work? A Review of the Research. J Engr Education. 93(3): 223-31.

38. Weaver Gc. Sturtevant. 2015. Design, Implementation, and Evaluation of a Flipped Format General Chemistry Course J. Chem. Educ, 92 (9): 1437-1448

39. Ryan, MD, Reid SA. 2016. Impact of the Flipped Classroom on Student Performance and Retention: A Parallel Controlled Study in General Chemistry. Journal of Chemical Education, 93 (1): 13-23 
40. Winquist JR. Carlson KA. 2014. Flipped Statistics Class Results: Better Performance Than Lecture Over One Year Later. Journal of Statistics Education 22 (3): pages

41. Ojennus, DD. 2016. Assessment of Learning Gains in a Flipped Biochemistry Classroom Biochemistry and Molecular Biology Education, 44 (1): 20-27

42. Zappe S, Leicht R, Messner J, Litzinger T, Woo LH. 2009. “Flipping” the Classroom to Explore Active Learning in a Large Undergraduate Course. Proceedings of the American Society for Engineering Education Conference \& Exhibition June 14-17; Austin, Texas. 